\title{
Evaluation of Renewable Energy Technology Based on Reliability Attributes Using Hybrid Fuzzy Dynamic Decision-Making Model
}

\author{
Daniel O. Aikhuele ${ }^{1}(\mathbb{D}) \cdot$ Desmond Eseoghene Ighravwe $^{1} \cdot$ Daniel Akinyele $^{2}$
}

Received: 11 March 2019 / Accepted: 7 November 2019 / Published online: 25 November 2019

(C) Springer Nature Singapore Pte Ltd. 2019

\begin{abstract}
Socio-technical and economic attributes consideration are very important during a renewable energy technology selection for a community. When decision-makers considered these attributes under a dynamic nature, they arrive at a robust decision. Hence, this study proposes an integrated model for renewable energy technologies evaluation under a dynamic condition. We developed the model using dynamic intuitionistic fuzzy Einstein geometric averaging operator, intuitionistic fuzzy entropy, and the intuitionistic fuzzy technique for order of preference by similarity to ideal solution method (TOPSIS). This model's applicability was tested using five renewable energy technologies - solar $\left(\mathrm{PT}_{1}\right)$, wind $\left(\mathrm{PT}_{2}\right)$, hydroelectricity $\left(\mathrm{PT}_{3}\right)$, geothermal $\left(\mathrm{PT}_{4}\right)$ and biomass $\left(\mathrm{PT}_{5}\right)$ and five attributes (risk factor, payback reliability, social benefit, change in demand and cost). Based on five energy experts, from academia and industry, opinions, the proposed model identified biomass energy technology as the most suitable energy technology. Three existing multi-criteria models were used to verify the proposed model; the proposed model performance was consistent with the existing models' results. From most suitable the least suitable, the model ranked these technologies $\mathrm{PT}_{5}>\mathrm{PT}_{2}>\mathrm{PT}_{3}>\mathrm{PT}_{1}>\mathrm{PT}_{4}$.
\end{abstract}

Keywords Renewable energy technology $\cdot$ Integrated model $\cdot$ Fuzzy logic $\cdot$ Decision-making process

\section{Introduction}

In recent times, researchers and practitioners have proffered several solutions to the distribution network management, for example, they have made a call for the need to integrate renewable energy systems into distributed networks. This call has the potential to change how conventional distributed networks are being managed, especially in terms of low voltage management [1]. Conventionally, transformers are used to step-up the amount of energy to be transmitted over a long distance. Thus, energy experts have encouraged the use of sub-stations for improved energy distribution in a community. Such sub-stations are used to manage the loads on a

Daniel O. Aikhuele

danbishop_22@yahoo.co.uk

1 Department of Mechanical \& Biomedical Engineering, Bells University of Technology, Ota, Nigeria

2 Department of Electrical Engineering, Bells University of Technology, Ota, Nigeria distributed network, visa-vice the installation of step-down transformers in these stations [2].

Apart from technical issues that have caused changes in energy system management, this system structure and operation is affected by ideological and finance factors [3]. For example, the innovation in renewable energy technologies has changed the orientation of how energy generated, transmitted and distributed across the world. And this has increased the interest in distributed systems. It is now a common experience to see a facility is run on a national grid and a stand-alone renewable energy source. In most cases, they require this to enhance the safety, reliability and efficiency of a facility. Thus, a detailed evaluation of the characteristics of facilities that are connected to a national grid and renewable energy sources must be carried to select a suitable renewable energy technology. While the short-run benefits of this evaluation will be improved facility efficiency - technical benefit, the long-term benefits will be both economic and environmental, and social to a facility owner(s) and host community $[4,5]$. Thus, energy experts now approach renewable energy analysis from a multi-criteria perspective $[6,7]$. 
Several authors have contributed to the selection of emerging renewable energy technology and system, among them, we can mention. Ahmad and Tahar [8] suggested that analytic hierarchy process (AHP), a multi-criteria tool, should be used to select a renewable energy source during an analysis of an electricity generation system. Amer and Daim [9] used AHP to select and prioritise renewable energy technologies. Gnaneswar Gude et al. [10] analysed the parameters that affect the selection of emerging energy technology and system. They placed emphasis on technical support, remoteness, plant capacity, feed-water salinity, grid and infrastructure availability, and renewable resources. Al-Jabr and Ben-Mansour [11] presented a robust cost-based approach that can be used to select a renewable energy system. Zhang and Tao [7] used AHP and data envelopment analysis (DEA) method to generate a model that can be used to evaluate and select renewable energy technology under a multi-criteria scenario.

Still, on the application of AHP, Stojanovi [12] used AHP to select a renewable energy system when considering economic, technical, social and environmental factors of a system. Yazdani-Chamzini et al. [13] presented an integrated model, that combined AHP and COPRAS (complex proportional assessment) method, for renewable energy project selection. In the model, AHP was used to determine criteria importance, while COPRAS was used to rank renewable energy projects. Cristóbal [14] used a combined AHP-VIKOR (AHP -VIseKriterijumska Optimizacija I Kompromisno Resenje) model to select a renewable energy system with respect to a renewable energy plan of a community. Anagnostopoulos et al. [15] carried out a sustainability analysis of renewable energy policies. They explored the use of multi-criteria decision-making (MCDM) and fuzzy logic to rank different energy policies.

Based on the mentioned studies above, the MCDM methods have proven to be an effective problem-solving tool for power and energy issues and selection. However, limited consideration has been given to the issue of uncertainty during renewable energy technologies analysis. Also, the methods become ineffective when the renewable energy technologies and systems need to be evaluated and selected under a dynamic process and conditions, that is, the condition at which the energy demand is constantly changing because of environmental conditions. Hence, this paper aims to develop a new model for the selection and evaluation of energy issues and selection by addressing the dynamic process and conditions because of the changing environmental conditions.

In this paper, an integrated model of dynamic intuitionistic fuzzy Einstein geometric averaging (DIFWG $\epsilon$ ) operator, intuitionistic fuzzy entropy (IFE) and the Intuitionistic Fuzzy Technique for Order of Preference by Similarity to Ideal Solution (IFTOPSIS) method is proposed. For the selection and evaluation of a suitable reliability-based emerging renewable energy technology and system to address the different environmental conditions. Some contributions of the proposed method include:

i. It addresses and account for uncertainty in the decisionmaking process, which is a major drawback in currently existing models used for the selection and evaluation of emerging energy technology and system.

ii. It uses a DIFWG $€$ operator to aggregate expert's opinions about the emerging energy technologies and systems and the used of IFTOPSIS for evaluating and ranking the alternatives, which to the best knowledge is novel in the selection of emerging energy technology and system and

iii. It uses an intuitionistic fuzzy entropy to compute the dynamic attributes weight.

\section{Preliminaries}

This section presents the definitions of IFS (Section 2.1), DIFWG $€$ operator (Sections 2.2 and 2.3), and FTOPSIS (Section 2.4).

\section{Intuitionistic Fuzzy Set}

Given that $A$ in $X=\{x\}$ is a non-empty fuzzy set, and it has a closed unit interval $I=[0,1]$. Equation (1) can be used to express this set as an IFS.

$A=\left\{\left\langle x, \mu_{A}(x), v_{A}(x)\right\rangle \mid x \in X\right\}$

This set membership function is mapped as where the mapping $\mu_{A}: X \rightarrow[0,1]$; it non-membership function is mapped as and $v_{A}: X \rightarrow[0,1]$, such that $0 \leq \mu_{A}(x)+v_{A}(x) \leq 1, \forall x \in X$ for each element $x \in X$ in $A$.

The nonempty set $=\{x\}$, which is an IFS, is expressed as Eq. (2).

$A=\left\{\left\langle x, \mu_{A}(x), 1-v_{A}(x)\right\rangle \mid x \in X\right\}$

The intuitionistic fuzzy hesitation (or the non-determinacy or uncertainty) degree of whether $x$ belong to $A$ or not is given as Eq. (3). This degree will arise when there is a relative lack of knowledge, personal error or uncertainty of any form, particularly when; $1-\mu_{A}(x)-v_{A}(x)=0$. For every element $x \in X$ in $A$, the IFS $A$ belongs to the fuzzy set, where $0 \leq \pi_{A} \leq 1$, hence, the intuitionistic fuzzy number(s) (IFN(s)) is given as $\alpha=\left(\mu_{A}, v_{A}, \pi_{A}\right)$ or as $\alpha=\left(\mu_{A}, v_{A}\right)$.

$\pi_{A}(x)=1-\mu_{A}(x)-v_{A}(x)$ 
Definition 2 [16] If the $I F N$ is given as $\alpha=\left(\mu_{A}, v_{A}, \pi_{A}\right)$ or as $\alpha=\left(\mu_{A}, v_{A}\right)$, then their operational laws are given as (4) to (7), when $\lambda>0$;

$$
\begin{aligned}
& A \cdot B=\left\{\left\langle x, \mu_{A}(x) \cdot \mu_{B}(x), v_{A}(x)+v_{B}(x)-v_{A}(x) \cdot v_{B}(x)\right\rangle \mid x \in X\right\} \\
& A+B=\left\{\left\langle x, \mu_{A}(x)+\mu_{B}(x)-\mu_{\mathrm{A}}(x) \cdot \mu_{B}(x), v_{A}(x) \cdot v_{B}(x)\right\rangle \mid x \in X\right\} \\
& \lambda A=\left\{\left\langle x, 1-\left(1-\mu_{A}(x)\right)^{\lambda},\left(v_{A}(x)\right)^{\lambda}\right\rangle \mid x \in X\right\}, \quad \lambda>0 . \\
& A^{\lambda}=\left\{\left\langle x,\left(\mu_{A}(x)\right)^{\lambda}, 1-\left(1-v_{A}(x)\right)^{\lambda}\right\rangle \mid x \in X\right\}, \quad \lambda>0
\end{aligned}
$$

\section{Intuitionistic Fuzzy Aggregation Operators}

Aggregation operators are used generally for summarizing information gathered from a variety of sources and in turn for making decisions. These operators are very useful for multi-criteria decision-making (MCDM) problems in engineering. Ordered weighted averaging (OWA) operator, which was developed by Yager [17] is among the early operators for MCDM problems. Different improvements have been made on OWA operator; two new versions of OWA are weighted OWA (WOWA) operator and its interpolation function [18], and the ordered weighted geometric averaging (OWGA) operator [19]. Other efforts that have been made on operator usage are reported in the works of Park et al. [20], Xu and Yager [21], Zhou and Chen [22], Aikhuele and Odofin [23], Gümüş and Bali [24], and Yin et al. [25].

Among these works, Gümüș and Bali's [24] is selected for the current problem. Based on its ability to address dynamic issues. Details of the DIFWGe operator [24] proposed for the selection and evaluation of a suitable reliability-based emerging energy technology and system to be connected to the LV network for maximum efficiency is given in the definition below.

Definition 3 [24] Given that $\alpha\left(t_{i}\right)=\left(\mu_{\alpha\left(t_{i}\right)}, v_{\alpha\left(t_{i}\right)}\right)$ is a set of IFN for $P$ different periods. And these periods have different weight vectors, $\delta=\left(\left(\delta\left(t_{1}\right), \delta\left(t_{2}\right), \delta\left(t_{3}\right), \ldots, \delta\left(t_{p}\right)\right)^{T}\right.$, such that $\sum_{i=1}^{n} \delta_{\left(t_{i}\right)}=1$ and DIFWG $\epsilon: \Omega^{n} \rightarrow \Omega$, if

$$
\begin{aligned}
\operatorname{DIFWG}_{\delta(t)}\left(\left(\delta\left(t_{1}\right), \delta\left(t_{2}\right), \delta\left(t_{3}\right), \ldots, \delta\left(t_{p}\right)\right)=\otimes_{i=1}^{p} \epsilon .\left(\delta_{i j}\left(t_{i}\right)\right)^{\delta\left(t_{i}\right)}\right. \\
=\left(\delta_{i j}\left(t_{1}\right)\right)^{\delta\left(t_{1}\right)} \bar{\otimes} \epsilon\left(\delta_{i j}\left(t_{2}\right)\right)^{\delta\left(t_{2}\right)} \bar{\bigotimes}_{\epsilon} \ldots . \bar{\bigotimes}_{\epsilon} \epsilon\left(\delta_{i j}\left(t_{p}\right)\right)^{\delta\left(t_{p}\right)} \\
=\left(\frac{2 \prod_{i}^{p}\left(\mu_{i j}\left(t_{i}\right)\right)^{\delta\left(t_{i}\right)}}{\prod_{i}^{p}\left(2-\mu_{i j}\left(t_{i}\right)\right)^{\delta\left(t_{i}\right)}+\prod_{i}^{p}\left(\mu_{i j}\left(t_{i}\right)\right)^{\delta\left(t_{i}\right)}}, \frac{\prod_{i}^{p}\left(1+v_{i j}\left(t_{i}\right)\right)^{\delta\left(t_{i}\right)}-\prod_{i}^{p}\left(1-v_{i j}\left(t_{i}\right)\right)^{\delta\left(t_{i}\right)}}{\prod_{i}^{p}\left(1+v_{i j}\left(t_{i}\right)\right)^{\delta\left(t_{i}\right)}+\prod_{i}^{p}\left(1-v_{i j}\left(t_{i}\right)\right)^{\delta\left(t_{i}\right)}}\right)
\end{aligned}
$$

\section{Intuitionistic Fuzzy Entropy}

Given fuzzy set $A$, which is intuitionistic, in a universe of discourse $X=\left\{x_{1}, x_{2}, x_{3}, \ldots, x_{n}\right\}$ be represented with an entropy measure $\mu_{\bar{A}}\left(x_{i}\right)=\left(\mu_{A}\left(x_{i}\right)+1-v_{A}\left(x_{i}\right)\right) / 2$. Equation (8) can be used to expression the intuitionistic fuzzy entropy of this set [26].

$E(A)=\frac{1}{n} \sum_{i=1}^{n}\left\{\left\{\operatorname{Sin} \frac{\pi^{*}\left[1+\mu_{A}\left(x_{i}\right)-v_{A}\left(x_{i}\right)\right]}{4}+\operatorname{Sin} \frac{\pi^{*}\left[1-\mu_{A}\left(x_{i}\right)+v_{A}\left(x_{i}\right)\right]}{4}-1\right\} * \frac{1}{\sqrt{2}-1}\right\}$

Based on this expression, the unknown weights of different attributes can be determined using Eq. (10).

$W_{j}=\frac{1-H_{j}}{n-\sum_{j=0}^{n} H_{j}}$

where $W_{j} \in[0,1], \sum_{j=1}^{n} W_{j}=1, H_{j}=\frac{1}{m} E\left(A_{j}\right)$ and $0 \leq H_{j} \leq 1$ for $(j=1,2,3, \ldots, n)$.

\section{Intuitionistic Fuzzy Technique for Order of Preference by Similarity to Ideal Solution (IF-TOPSIS)}

IF-TOPSIS is one of the most widely used MCDM techniques [27]. It measures distances in the Euclidean norm, which implicitly assume all contemplated attributes are independent. This paper adopted IF-TOPSIS model, which was originally proposed by Hung and Chen [28], to as a framework in 
Table 1 Scare of linguistic variables

\begin{tabular}{ll}
\hline Linguistic variables & IFN \\
\hline Really low (R) & $(0.65,0.10)$ \\
Low (L) & $(0.70,0.20)$ \\
High (H) & $(0.80,0.10)$ \\
Very High (V) & $(0.85,0.15)$ \\
Really Very High (RH) & $(0.95,0.20)$ \\
\hline
\end{tabular}

presenting the proposed integrated model. Given a multicriteria problem with a set of alternatives $\left(P T=P T_{1}, P T_{2}\right.$, $\left.P T_{3} \ldots . P T_{n}\right)$, and a set of attributes $\left(A T=A T_{1}, A T_{2}, A T_{3} \ldots\right.$. $A T_{n}$ ) are required to select the most suitable alternative for the problem, the proposed model can be used to solve this problem if the weight of the attributes is unknown and the evaluation needs to be carried out in a dynamic process due to changes in the attributes. To solve this problem with the DIFWG $€$ operator, IFE and the IFTOPSIS method, which formed the integrated model, the following steps are required:

Step 1. Constitute a group of experts with relevant experience and expertise in emerging energy technology. To ensure accuracy in the evaluation, choose experts from the academic and from the industry.

Step 2. Construct an intuitionistic fuzzy decision matrix $\left(A S_{m x n}\left(x_{i j}\right)\right.$ using preferences information from the experts (Eq. 11). And covert the information $\left(A S_{m x n}\left(x_{i j}\right)\right)$, which are linguistic variables, to the intuitionistic fuzzy number (IFN), see Table 1.

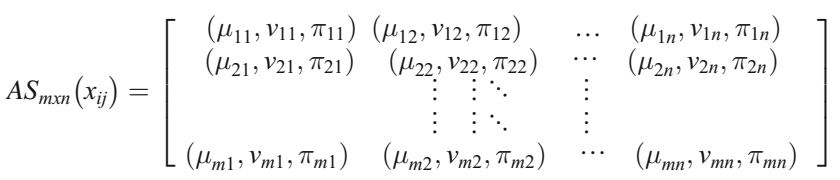

Step 3. Use the DIFWGe operator, which is Eq. (8), to construct the collective decision matrix $\left(R_{p k}\left(x_{i j}\right)\right)$.

Step 4. Use Eqs. 9 and 10 to compute the weights vectors of the evaluating attributes.
Step 5. Use the weights vectors in Step 4 to construct a weighted normalization from the collective decision matrix $\left(R_{p k}\left(x_{i j}\right)\right)$.

Step 6. Use Eqs. (12) and (13) to calculate the alternatives positive ideal (PI) and negative ideal (NI) solutions, respectively.

$P T^{+}=\left\{\left\langle\begin{array}{c}A T_{j},\left(\left(\max _{i j}\left(A T_{j}\right) \mid j \in Z\right),\left(\min _{i j}\left(A T_{j}\right) \mid j \epsilon G\right)\right) \\ \left(\left(\operatorname{minv}_{i j}\left(A T_{j}\right) \mid j \in Z\right),\left(\operatorname{maxv}_{i j}\left(A T_{j}\right) \mid j \in G\right)\right)\end{array}\right\rangle \mid i \in m\right\}$

$\left.P T^{-}=\left\{\begin{array}{c}A T_{j},\left(\left(\min _{i j}\left(A T_{j}\right) \mid j \in Z\right),\left(\max _{i j}\left(A T_{j}\right) \mid j \in G\right)\right), \\ \left(\left(\operatorname{maxv}_{i j}\left(A T_{j}\right) \mid j \in Z\right),\left(\operatorname{minv}_{i j}\left(A T_{j}\right) \mid j \in G\right)\right)\end{array}\right\rangle \mid i \in m\right\}$

where $Z$ and $\mathrm{G}$ denote the collection of benefit and cost attributes, respectively.

Step 7. Use the intuitionistic Euclidean distance method to calculate the alternatives distances based on their PI and NI solutions.

$d_{I F S}\left(P T^{+}\right)=\sqrt{\sum_{j=1}^{n}\left[\left(\mu_{i j}\left(A T_{j}\right)-\mu_{\left(P T^{+}\right)}\left(A T_{j}\right)\right)^{2}+\left(v_{i j}\left(A T_{j}\right)-v_{\left(P T^{+}\right)}\left(A T_{j}\right)\right)^{2}\right]}$

$d_{I F S}\left(P T^{-}\right)=\sqrt{\sum_{j=1}^{n}\left[\left(\mu_{i j}\left(A T_{j}\right)-\mu_{\left(P T^{\top}\right)}\left(A T_{j}\right)\right)^{2}+\left(v_{i j}\left(A T_{j}\right)-v_{\left(P T^{\top}\right)}\left(A T_{j}\right)\right)^{2}\right]}$

Step 8. Calculate the alternatives' closeness coefficient (CC).

$C C_{i}=\frac{d_{I F S}\left(P T^{-}\right)}{d_{I F S}\left(P T^{-}\right)+d_{I F S}\left(P T^{+}\right)}$

Step 9. Rank the alternatives using a higher-the-better concept.

Table 2 Intuitionistic fuzzy decision matrix

\begin{tabular}{|c|c|c|c|c|c|c|c|c|c|c|c|c|c|c|c|c|c|c|c|c|c|c|c|c|c|}
\hline & $\begin{array}{l}\mathrm{J} 1 \\
A T_{1}\end{array}$ & $\mathrm{~J} 2$ & $\mathrm{~J} 3$ & $\mathrm{~J} 4$ & $\mathrm{~J} 5$ & $\begin{array}{l}\mathrm{J} 1 \\
A T_{2}\end{array}$ & $\mathrm{~J} 2$ & $\mathrm{~J} 3$ & $\mathrm{~J} 4$ & J5 & $\begin{array}{l}\mathrm{J} 1 \\
A T_{3}\end{array}$ & $\mathrm{~J} 2$ & $\mathrm{~J} 3$ & $\mathrm{~J} 4$ & J5 & $\begin{array}{l}\mathrm{J} 1 \\
A T_{4}\end{array}$ & $\mathrm{~J} 2$ & $\mathrm{~J} 3$ & $\mathrm{~J} 4$ & J5 & $\begin{array}{l}\mathrm{J} 1 \\
A T_{5}\end{array}$ & $\mathrm{~J} 2$ & $\mathrm{~J} 3$ & $\mathrm{~J} 4$ & J5 \\
\hline$P T_{1}$ & $\mathrm{R}$ & $\mathrm{L}$ & $\mathrm{L}$ & $\mathrm{H}$ & $\mathrm{L}$ & $\mathrm{V}$ & $\mathrm{L}$ & $\mathrm{RH}$ & $\mathrm{H}$ & $\mathrm{L}$ & $\mathrm{RH}$ & $\mathrm{H}$ & $\mathrm{R}$ & $\mathrm{V}$ & $\mathrm{H}$ & $\mathrm{R}$ & $\mathrm{H}$ & $\mathrm{H}$ & $\mathrm{V}$ & $\mathrm{H}$ & $\mathrm{RH}$ & $\mathrm{H}$ & $\mathrm{V}$ & $\mathrm{L}$ & $\mathrm{RH}$ \\
\hline$P T_{2}$ & $\mathrm{R}$ & $\mathrm{H}$ & $\mathrm{H}$ & $\mathrm{V}$ & $\mathrm{H}$ & $\mathrm{RH}$ & $\mathrm{H}$ & $\mathrm{R}$ & VH & $\mathrm{H}$ & $\mathrm{H}$ & $\mathrm{V}$ & V & $\mathrm{L}$ & $\mathrm{V}$ & $\mathrm{H}$ & $\mathrm{V}$ & $\mathrm{V}$ & $\mathrm{L}$ & $\mathrm{V}$ & $\mathrm{L}$ & $\mathrm{V}$ & $\mathrm{RH}$ & $\mathrm{L}$ & $\mathrm{RH}$ \\
\hline$P T_{3}$ & $\mathrm{H}$ & $\mathrm{V}$ & $\mathrm{V}$ & $\mathrm{L}$ & $\mathrm{V}$ & $\mathrm{H}$ & $\mathrm{H}$ & $\mathrm{L}$ & $\mathrm{RH}$ & $\mathrm{V}$ & $\mathrm{R}$ & $\mathrm{V}$ & $\mathrm{H}$ & $\mathrm{V}$ & $\mathrm{H}$ & $\mathrm{V}$ & $\mathrm{L}$ & $\mathrm{H}$ & $\mathrm{R}$ & $\mathrm{R}$ & $\mathrm{R}$ & $\mathrm{H}$ & $\mathrm{H}$ & $\mathrm{V}$ & $\mathrm{H}$ \\
\hline$P T_{4}$ & $\mathrm{~V}$ & $\mathrm{H}$ & $\mathrm{RH}$ & $\mathrm{R}$ & $\mathrm{RH}$ & $\mathrm{V}$ & $\mathrm{L}$ & $\mathrm{H}$ & $\mathrm{R}$ & $\mathrm{RH}$ & $\mathrm{RH}$ & $\mathrm{H}$ & V & $\mathrm{R}$ & $\mathrm{V}$ & $\mathrm{R}$ & $\mathrm{L}$ & $\mathrm{L}$ & $\mathrm{H}$ & $\mathrm{L}$ & $\mathrm{V}$ & $\mathrm{L}$ & $\mathrm{H}$ & $\mathrm{R}$ & $\mathrm{RH}$ \\
\hline$P T_{5}$ & $\mathrm{RH}$ & $\mathrm{H}$ & $\mathrm{H}$ & $\mathrm{V}$ & $\mathrm{V}$ & $\mathrm{RH}$ & $\mathrm{H}$ & VH & $\mathrm{L}$ & $\mathrm{RH}$ & $\mathrm{L}$ & $\mathrm{V}$ & RH & $\mathrm{L}$ & $\mathrm{R}$ & $\mathrm{RH}$ & $\mathrm{H}$ & $\mathrm{R}$ & $\mathrm{V}$ & $\mathrm{H}$ & RH & $\mathrm{H}$ & $\mathrm{R}$ & $\mathrm{V}$ & $\mathrm{H}$ \\
\hline
\end{tabular}


Table 3 The attributes' decision matrix and vector weights

\begin{tabular}{llllll}
\hline & $A T_{1}$ & $A T_{2}$ & $A T_{3}$ & $A T_{4}$ & $A T_{5}$ \\
\hline$P T_{1}$ & $(0.4294,0.3526)$ & $(0.5515,0.3601)$ & $(0.5490,0.2652)$ & $(0.5721,0.2492)$ & $(0.6381,0.3716)$ \\
$P T_{2}$ & $(0.5721,0.2492)$ & $(0.5490,0.2652)$ & $(0.5754,0.3450)$ & $(0.5754,0.3450)$ & $(0.6595,0.4081)$ \\
$P T_{3}$ & $(0.5754,0.3450)$ & $(0.6319,0.3528)$ & $(0.5863,0.2651)$ & $(0.5438,0.3143)$ & $(0.5721,0.2492)$ \\
$P T_{4}$ & $(0.6367,0.3298)$ & $(0.5438,0.3143)$ & $(0.5536,0.2867)$ & $(0.4294,0.3526)$ & $(0.5438,0.3143)$ \\
$P T_{5}$ & $(0.6451,0.2928)$ & $(0.6381,0.3716)$ & $(0.6595,0.4081)$ & $(0.5490,0.2652)$ & $(0.5490,0.2652)$ \\
Weight & 0.044759 & 0.037436 & 0.043581 & 0.034803 & 0.043631 \\
\hline
\end{tabular}

\section{Numerical Illustration}

This article uses a community in Lagos, Nigeria as its case study. It is because of the call for the authority to invest in renewable (emerging) energy technology to replace and improve the present epileptic electricity over the past years. Based on discussion with the community's local authorities, they desire to invest some of their resources in a renewable energy technology in the coming year. From our feasibility study, solar $\left(P T_{1}\right)$, wind $\left(P T_{2}\right)$, hydroelectricity $\left(P T_{3}\right)$, geothermal $\left(P T_{4}\right)$ and biomass $\left(P T_{5}\right)$ energy technologies are the available renewable energy technologies for this community. Waves energy technology, which is a renewable energy technology, was not considered because it is sparse in Nigeria. In selecting the best renewable energy technology for the councils in the district, the following five reliability-based attributes are considered: risk factor $\left(\left(A T_{1}\right)\right.$, payback period $\left(A T_{2}\right)$, social benefit $\left(A T_{3}\right)$, change in demand $\left(A T_{4}\right)$, and cost $\left(A T_{5}\right)$. Several of the studies on renewable energy technology in Nigeria have considered these attributes, but not under a dynamic condition as presented in this article ([29]; Ighravwe \& Oke, [30]; [31, 32]).

Due to the changing demand of the community's electricity consumption, these technologies selection and evaluation carried out with a dynamic process. To achieve this, five experts $(\mathrm{J} 1, \mathrm{~J} 2, \mathrm{~J} 3, \mathrm{~J} 4$ and $\mathrm{J} 5)$ from academic and industry were asked to evaluate the renewable energy technologies for the last 10 years - 2009 to 2018. These periods were divided into two intervals and the weighting vector for the periods were aggregated and given as $\delta(t)=\{0.167,0.333,0.500,0.630,0.652\}$. These values, aggregated were obtained using the membership rating scale originally presented in Aikhuele and Turan [27, 33]. Based on the algorithm presented in Section 3 and the linguistic variables in Table 1, the experts were able to rate the renewable energy technologies. Table 2 shows the information obtained from the experts.

The linguistic variables in Table 2 were converted to IFN and aggregated to construct the collective decision matrix $\left(R_{p k}\left(x_{i j}\right)\right)$ using the DIFWG $\epsilon$ operator. Table 3 shows the result of the constructed collective decision matrix (aggregation). Furthermore, Eqs. 9 and 10 were used to calculate the vector's weights of the reliabilitybased attributes.

In order to generate the positive ideal solution for the current problem, Eq. (14) was used to generate the alternatives' weighted normalized values. The weighted normalized values in Table 4 were also used to generate the negative ideal solutions using Eq. (15). And Eq. (16) was used to determine the renewable energy technologies' closeness coefficients (Table 5).

\section{Discussion of Results}

Using a higher-the-better concept, Table 5 shows that these technologies can be ranked as follows: $\mathrm{PT}_{5}>\mathrm{PT}_{2}>\mathrm{PT}_{3}>$ $\mathrm{PT}_{4}>\mathrm{PT}_{1}$. To validate this ranking order, the MCDM approaches in Liu et al. [34], Zhang et al. [35], and Gümüş and Bali [24] were used to solve the same problem. Table 6 shows these approaches results for the renewable energy technology problem. The results in this table show that the most suitable technology is $\mathrm{PT}_{5}$ and $\mathrm{PT}_{4}$ is the least suitable renewable energy technology. These results are consistent with the
Table 4 The weighted normalization matrix

\begin{tabular}{llllll}
\hline & $A T_{1}$ & $A T_{2}$ & $A T_{3}$ & $A T_{4}$ & $A T_{5}$ \\
\hline$P T_{1}$ & $(0.0192,0.0158)$ & $(0.0206,0.0135)$ & $(0.0239,0.0116)$ & $(0.0199,0.0087)$ & $(0.0278,0.0162)$ \\
$P T_{2}$ & $(0.0256,0.0112)$ & $(0.0206,0.0099)$ & $(0.0251,0.0150)$ & $(0.0200,0.0120)$ & $(0.0288,0.0178)$ \\
$P T_{3}$ & $(0.0258,0.0154)$ & $(0.0237,0.0132)$ & $(0.0255,0.0116)$ & $(0.0189,0.0109)$ & $(0.0250,0.0109)$ \\
$P T_{4}$ & $(0.0285,0.0148)$ & $(0.0204,0.0118)$ & $(0.0241,0.0125)$ & $(0.0149,0.0123)$ & $(0.0237,0.0137)$ \\
$P T_{5}$ & $(0.0289,0.0131)$ & $(0.0239,0.0139)$ & $(0.0287,0.0178)$ & $(0.0191,0.0092)$ & $(0.0240,0.0116)$ \\
\hline
\end{tabular}


Table 5 The closeness coefficient of the alternatives

\begin{tabular}{llll} 
& $d_{I F S}\left(P T^{+}\right)$ & $d_{I F S}(P T)$ & $C C_{i}$ \\
\hline$P T_{1}$ & 0.02219 & 0.01646 & 0.4258 \\
$P T_{2}$ & 0.01552 & 0.02254 & 0.5923 \\
$P T_{3}$ & 0.01931 & 0.01936 & 0.5006 \\
$P T_{4}$ & 0.02248 & 0.01595 & 0.4151 \\
$P T_{5}$ & 0.01326 & 0.02611 & 0.6632 \\
\hline
\end{tabular}

proposed model's results. Also, we observed that the fourth most suitable technology $\left(\mathrm{PT}_{1}\right)$ with respect to Gümüs and Bali [24] and Zhang et al. [35] results in Table 6 are the same as that of our model.

The study not only revealed the suitability of the proposed model for ranking renewable energy technologies but reveals its suitability for selecting a reliability-based energy technology under a dynamic environment.

\section{Conclusions}

This study uses DIFWGє operator, IFE and IFTOPSIS method to proposed a novel MCDM model proposed for the selection and evaluation of a suitable reliability-based renewable energy technology and system to address the dynamic environmental conditions in Lagos central district. The main advantage and contribution of the proposed model to the selection and evaluation study for the renewable energy technology and system include the ability of the model to address and account for uncertainty in the decision-making process, which is a major drawback in existing models used that are suitable for renewable energy technology selection. Other contributions of this work are the use of a DIFWG $\epsilon$ operator to aggregate expert's opinions about the renewable energy technologies and systems and the used of IFTOPSIS to evaluate and rank these technologies, which to the best knowledge is novel in the selection of emerging renewable energy technology and system. In addition to the above-mentioned benefits, the proposed model accounts for and addresses the dynamic issues in the evaluation and selection of renewable energy technology

Table 6 The technologies closeness coefficients and ranks

\begin{tabular}{|c|c|c|c|c|c|c|}
\hline & \multicolumn{2}{|c|}{ Gümüș and Bali [24] } & \multicolumn{2}{|c|}{ Liu et al. [34] } & \multicolumn{2}{|c|}{ Zhang et al. [35] } \\
\hline & $S\left(r_{i}\right)$ & Ranking & $Q_{i}$ & Ranking & $S\left(r_{i}\right)$ & Ranking \\
\hline$P T_{1}$ & 0.2226 & 4 & 0.6747 & 3 & 0.5982 & 4 \\
\hline$P T_{2}$ & 0.2597 & 3 & 0.7555 & 4 & 0.6193 & 3 \\
\hline$P T_{3}$ & 0.2765 & 2 & 0.2284 & 2 & 0.6243 & 2 \\
\hline$P T_{4}$ & 0.2195 & 5 & 1.0000 & 5 & 0.5960 & 5 \\
\hline$P T_{5}$ & 0.2819 & 1 & 0.0000 & 1 & 0.6320 & 1 \\
\hline
\end{tabular}

and system and finally, the used of intuitionistic fuzzy entropy for computing the weights vectors of the dynamic attributes.

A case study of renewable energy technologies evaluation was used to test the performance of the proposed model. The result from the evaluation is presented in Table 5 and it shows that biomass energy technology $\left(P T_{5}\right)$ is the most suitable energy source for the Lagos central district, based on the reliability attributes and the proposed integrated model, which evaluate the renewable energy technologies under a dynamic process. The proposed model results were compared with selected models in MCDM literature, we observed that our model selected the same most suitable technology as the existing models. In the future, the model will be applied in other domains.

A further study can extend the scope of the proposed model using criteria that deal with the environmental impact of renewable energy technology. Also, further study can consider the design requirements for the identified criteria when evaluating renewable energy technology. This problem might require the use of other MCDM tools, such as an axiomatic method.

\section{Compliance with Ethical Standards}

Conflict of Interest The authors declare that they have no conflict of interest.

\section{References}

1. Walling RA, Saint R, Dugan RC, Burke J, Kojovic LA (2008) Summary of distributed resources impact on power delivery systems. IEEE Transactions on Power Delivery 23(3):1636-1644

2. Siemens AG (2012) Power Engineering Guide. Siemens. 132:297311. https://doi.org/10.1007/s10342-012-0675-9

3. Saxena D, Singh S, Verma K (2010) Application of computational intelligence in emerging power systems. Int J Eng Sci Technol 2(3): 1-7. https://doi.org/10.4314/ijest.v2i3.59166

4. Husain AAF, Hasan WZW, Shafie S, Hamidon MN, Pandey SS (2018) A review of transparent solar photovoltaic technologies. Renew Sust Energ Rev 94(3):779-791. https://doi.org/10.1016/j. rser.2018.06.031

5. Matsuo Y, Yanagisawa A, Yamashita Y (2013) A global energy outlook to 2035 with strategic considerations for Asia and Middle East energy supply and demand interdependencies. Energy Strategy Reviews 2(1):79-91

6. Ighravwe DE, Babatunde MO (2018) Selection of a renewable mini-grid energy source in for developing countries: a risk-based multi-criteria approach. Journal of Renewable Energy. https://doi. org/10.1155/2018/2163262

7. Zhang LB, Tao Y (2014) The Evaluation and Selection of Renewable Energy Technologies in China,Energy Procedia, vol 61. Elsevier B.V., pp 2554-2557. https://doi.org/10.1016/j. egypro.2014.12.044

8. Ahmad S, Tahar RM (2014) Selection of renewable energy sources for sustainable development of electricity generation system using analytic hierarchy process: a case of Malaysia. Renew Energy 63: 458-466. https://doi.org/10.1016/j.renene.2013.10.001 
9. Amer M, Daim TU (2011) Selection of renewable energy technologies for a developing county: a case of Pakistan. Energy for Sustainable Development 15(4):420-435

10. Gnaneswar Gude V, Nirmalakhandan N, Deng S (2010) Renewable and sustainable approaches for desalination renew. Renew Sust Energ Rev 14(9):2641-2654

11. Al-Jabr AH, Ben-Mansour R (2018) Optimum selection of renewable energy powered desalination systems. Proceedings 2(11):612. https://doi.org/10.3390/proceedings 2110612

12. Stojanovi M (2013) Multi-criteria decision-making for selection of renewable energy systems. Safety Engineering 3(3):115-120. https://doi.org/10.7562/SE2013.3.02.02

13. Yazdani-Chamzini A, Fouladgar MM, Zavadskas EK, Moini SHH (2013) Selecting the optimal renewable energy using multi criteria decision making. J Bus Econ Manag 14(5):957-978. https://doi. org/10.3846/16111699.2013.766257

14. Cristóbal JRS (2011) Multi-criteria decision-making in the selection of a renewable energy project in Spain: the Vikor method. Renew Energy 36:498-502

15. Anagnostopoulos K, Doukas H, Psarras J (2007) A logic-based fuzzy multicriteria decision support system using the ideal and the anti-ideal solutions: assessing the sustainability of renew- able energy policies. Advances in Fuzzy Sets and Systems 2(3):239-266

16. Atanassov KT (1994) New operations defined over the intuitionistic fuzzy sets. Fuzzy Sets Syst 61(2):137-142. https:// doi.org/10.1016/0165-0114(94)90229-1

17. Yager RR (1988) On ordered weighted averaging aggregation operators in multi criteria decision making. IEEE Trans Syst Man Cybern 18(1):183-190. https://doi.org/10.1109/21.87068

18. Torra V (2000) The WOWA operator and the interpolation function W*: Chen and Otto's interpolation method revisited. Fuzzy Sets Syst 113(3):389-396. https://doi.org/10.1016/S0165-0114(98) 00040-2

19. Xu ZS, Da QL (2002) The ordered weighted geometric averaging operators. Int J Intell Syst 17(7):709-716. https://doi.org/10.1002/ int. 10045

20. Park, J. H., Kwun, Y. C., \& Koo, J. H. (2011). Dynamic uncertain linguistic weighted harmonic mean operators applied to decision making. In Proceedings 2011 International Conference on System Science and Engineering, ICSSE 2011 (pp. 101-106). https://doi. org/10.1109/ICSSE.2011.5961882

21. Xu Z, Yager RR (2008) Dynamic intuitionistic fuzzy multi-attribute decision making. Int J Approx Reason 48(1):246-262. https://doi. org/10.1016/j.ijar.2007.08.008

22. Zhou L, Chen H (2014) Generalized ordered weighted proportional averaging operator and its application to group decision making. Informatica 25(2):327-360

23. Aikhuele DO, Odofin S (2017) A generalized triangular intuitionistic fuzzy geometric averaging operator for decisionmaking in engineering and management. Information 8(3):1-17. https://doi.org/10.3390/info8030078
24. Gümüș S, Bali O (2017) Dynamic aggregation operators based on intuitionistic fuzzy tools and Einstein operations. Fuzzy Information and Engineering 9(1):45-65. https://doi.org/10.1016/ j.fiae.2017.03.003

25. Yin K, Wang P, Jin X (2018) Dynamic intuitionistic fuzzy multiattribute group decision-making or and prediction model. Symmetry 10(11):536. https://doi.org/10.3390/sym10110536

26. Ye J (2010) Two effective measures of intuitionistic fuzzy entropy. Computing (Vienna/New York) 87(1-2):55-62. https://doi.org/10. 1007/s00607-009-0075-2

27. Aikhuele DO, Turan FM (2017a) A modified exponential score function for troubleshooting an improved locally made offshore patrol boat engine. Journal of Marine Engineering \& Technology. https://doi.org/10.1080/20464177.2017.1286841

28. Hung, C.-C., \& Chen, L.-H. (2009). A Fuzzy TOPSIS Decision Making Model with Entropy Weight under Intuitionistic Fuzzy Environment. Proceedings of the International MultiConference of Engineers and Computer Scientists IMECS 2009, Hong Kong, I, 18-21

29. Akinyele, D. O., Olatomiwa, L., Ighravwe, D. E., Babatunde, M. O., Monyei, C., \& Abiodun, O. (2019). Evaluation of solar PV microgrid deployment sustainability in rural areas: a fuzzy STEEP approach. IEEE PES/IAS Power Africa Conference

30. Ighravwe, D. E., \& Oke, S. A. (2017). Optimal determination for cost of electric power generation and plant capacity of utilities. Walailak Journal of Science and Technology, 14(6) 463-484.

31. Ohunakin OS, Adaramola MS, Oyewola OM, Fagbenle RO (2014) Solar energy applications and development in Nigeria: drivers and barriers. Renew Sust Energ Rev 32:294-301

32. Olusola Babatunde S, Opawole A, Emmanuel Akinsiku O (2012) Critical success factors in public-private partnership (PPP) on infrastructure delivery in Nigeria. J Facil Manag 10(3):212-225

33. Aikhuele DO, Turan FM (2017b) Extended TOPSIS model for solving multi-attribute decision making problems in engineering. Decision Science Letters 6:365-376. https://doi.org/10.5267/j.dsl. 2017.2.002

34. Liu H-C, Liu L, Liu N, Mao L-X (2012) Risk evaluation in failure mode and effects analysis with extended VIKOR method under fuzzy environment. Expert Syst Appl 39(17):12926-12934. https://doi.org/10.1016/j.eswa.2012.05.031

35. Zhang Z, Yang J, Ye Y, Hu Y, Zhang Q (2012) A type of score function on intuitionistic fuzzy sets with double parameters and its application to pattern recognition and medical diagnosis. In: Procedia Engineering, vol 29, pp 4336-4342. https://doi.org/10. 1016/j.proeng.2012.01.667

Publisher's Note Springer Nature remains neutral with regard to jurisdictional claims in published maps and institutional affiliations. 